\title{
The Influence of Mother's Rational Parenting Behavior on Academic Procrastination of Middle School Students: Effect of Mediated Moderation of Self-Control through Intrinsic Motivation
}

\author{
Eun Byeol Ahn ${ }^{1}$, Hee Hwa Kim ${ }^{2}$ \\ Ph. D. Candidate, Department of Child Development and Family Studies, Pusan National University, Busan, Korea \\ Professor, Department of Child Development and Family Studies, Pusan National University, Busan, Korea ${ }^{2}$ \\ 모의 합리적 양육이 중학생의 학업지연행동에 미치는 영향: \\ 내재적 동기를 통한 자기 통제력의 매개된 조절효과 \\ 안은별 ${ }^{1}$, 김희화 ${ }^{2}$ \\ 부산대학교 아동가족학과 박사수료 ${ }^{1}$, 부산대학교 아동가족학과 교수 ${ }^{2}$
}

\begin{abstract}
Objectives: This study aimed to examine the effect of intrinsic motivation and mother's rational parenting behavior on academic procrastination of middle school students, and to verify the mediated moderation effect of self-control.

Methods: The participants of this study includes children ages 13 through 14 years old $(N=267)$; all of whom attend school in Busan, S. Korea. Collected data were used analyzed by the SPSS 25.0 and PROCESS MACRO (mode l8) by Hayes (2013).

Results: The relationship of mother's rational parenting behavior with the academic procrastination level was mediated by self-control. Additionally, intrinsic motivation level moderated the relationship between mother's rational parenting behavior and academic procrastination. Further, level of intrinsic motivation had a mediated moderation effect from mother's rational parenting behavior to the academic procrastination, through the self-control.

Conclusion: These results indicate that high level of intrinsic motivation is an important factor in preventing academic procrastination of middle school students.
\end{abstract}

Keywords: rational parenting behavior, academic procrastination, self-control, intrinsic motivation

\section{Introduction}

자신에게 주어진 일이나 과제를 해야 한다고 생각하면서도 마 감직전까지 과제의 시작이나 완성을 미루는 사람들을 볼 수 있다. 이는 '주관적 불편함을 느끼면서까지 불필요하게 과제 를 미루는 행동(Solomon \& Rothblum, 1984)'인 지연행동으로, 특히 학업영역에서 성취를 이루어야 하는 학생들에게서 많이

Corresponding Author: Hee Hwa Kim, Professor, Department of Child Development \& Family Studies, Pusan National University, 2, Busandaehak-ro 63beongil, Geumjeong-gu, Busan, Korea

E-mail: hwakim@pusan.ac.kr
나타난다. 이러한 지연행동이 학업장면에서 나타나 예정된 시 간까지 과제를 시작하거나 완성하는데 실패하는 것을 학업지 연행동이라고 한다(Ellis \& Knaus, 1977; Lay, 1986). 학업지연 행동은 학업에 대한 부정적 태도를 형성하며 스트레스, 불안 등과 같은 부정적 감정을 수반하여 저조한 학업성취를 초래 하고, 이는 진학 및 취업까지도 영향을 미치게 된다. 초등학교 에서 중학교로 전환하는 청소년이 경험하는 가장 큰 어려움

(c)The Korean Association of Child Studies

This is an Open Access article distributed under the terms of the Creative Commons Attribution Non-Commercial License (http:// creativecommons.org/licenses/by-nc/4.0) which permits unrestricted noncommercial use, distribution, and reproduction in any medium, provided the original work is properly cited. 
은 학업적 부담이며(Anderman \& Midgley, 1997) 학업적 부담 은 학생들이 해야 할 일을 나중으로 미루게 하는 원인이 된다 (Choo \& Lim, 2008). 이에 따라 학업적 부담이 증가하고, 학 업상황에 지속적으로 노출되기 시작하는 중학생을 대상으 로 한 학업지연행동에 대한 연구의 필요성이 제기되고 있다 (Beswick, Rothblum, \& Mann, 1988; Ferrari, 2000; Roh, 2011; Synn, Park, \& Seo, 2005).

최근 많은 연구들에서 부모의 양육행동과 자녀의 학업지 연행동 간의 관계에 초점을 맞추고 있다(H. Park \& Ahn, 2019; Wu \& Ahn, 2017; Yun \& Yeo, 2013). 부모의 양육행동은 학자 들에 따라 다양하게 구분되고 있으나, 양육행동에 대한 초기 구분은 Schaefer의 이론에 근거하여 Oh와 Lee (1982)가 개발한 애정-적대, 자율-통제, 성취-비성취, 합리-비합리 등으로 이루 어졌다. 이후 많은 연구들이 이 구분방식에 근거하여 자녀의 발달을 이해하고 있는 추세이다. 부모의 합리적 양육행동은 매사에 이유를 중시하고 자녀에게 일의 동기와 근거의 제시를 요구하며, 교육에 있어 이성적인 태도를 취하는 것으로 정의 된다. 즉, 자녀의 생활습관을 규제하면서도, 자녀들이 자율성 을 가질 수 있게 도와주므로 지연행동의 예방과 가장 관련이 높은 양육행동라고 볼 수 있다(Hwang, 2008). 부모의 양육행 동이 합리적일수록 아동의 지연행동이 감소하였으며(Hwang \& Jang, 2010; Seo, 2012), 부모의 합리적인 양육행동은 학업지 연행동과 부적상관을 나타내었다(K. Kim, 2016). 이와 같은 결 과들을 볼 때, 부모의 양육행동이 자녀의 학업지연행동에 영 향을 미치는 주요한 변인임을 알 수 있다. 부모 중에서도 자녀 와 보내는 시간이 상대적으로 많고, 대부분의 학교생활을 관 리해주고, 과제나 학업 영역에 관심 및 개입이 많은 어머니의 합리적 양육행동이 아버지보다 학업지연행동에 더 크게 미칠 것으로 생각된다. 따라서 본 연구에서는 청소년의 학업지연행 동에 영향을 미치는 어머니의 합리적 양육행동에 우선 관심을 두고자 한다.

학업지연행동은 완벽주의, 성취목표지향성, 실패공포, 자 기통제력 등과 같은 개인 내적 요인(Myeong, Lee, Yang, \& Lee, 2015; S. M. Park, Ham, \& Son 2016; Yang, 2017)에 의해서도 영 향을 받는다. 이 중 자기 통제력이란, 스스로 상황적인 요구에 적절한 행동을 할 수 있으며, 바람직하지 못하다고 느껴지는 충동을 스스로 억제하고, 더 좋은 결과를 위해 자신의 행동과 사고, 정서를 조절하며 만족을 자제하고 인내하는 능력이다 (Finkenauer, Engels, \& Baumeister, 2005; K.-N. Lee, 2000). 자기 통제력이 낮은 사람은 주의력이 부족하며 반응시간이 짧은 특 성이 있어 과제를 수행하는 동안 주변에 쉽게 주의를 빼앗겨
잦은 실수를 반복하거나, 비계획적으로 과제를 수행하여 제 시간 안에 완성하지 못하는 경우가 종종 있다. 반대로 자기통 제력 수준이 높은 경우, 자신의 삶에서 더 성공적으로 자기조 절을 하는 경향이 있다. Tangney, Baumeister와 Boone (2004) 의 연구에서 자기 통제력이 높은 사람들은 삶의 다양한 영역에 서 더욱 긍정적인 결과물을 산출하며, 인생에서 성공적인 경 험을 더욱 많이 하는 것으로 나타났다. J. U. Kim과 Yang (2013) 의 연구에서도 자기 통제력과 학업지연행동 간에 유의미한 부 적상관이 나타났으며 자기통제력, 자기효능감, 우울 중 자기 통제력이 학업 지연행동에 가장 많은 영향력을 보였다. 특히 자기 통제력은 아동의 발달에 맞춰 점차 발달하다가 청소년기 에는 사회에서 요구되는 수준으로 완성되는 것으로, 부모 양 육행동에 의해 많은 영향을 받는다. 어머니의 통제적인 양육 은 초기 청소년의 자기 통제력을 감소시키는(H.-R. Lee, Doh, $\mathrm{Kim}, \&$ Park, 2009) 반면, 청소년이 어머니의 양육행동을 합리 적으로 지각할 때 남녀 청소년의 자기 통제력은 향상되는 것 으로 나타났다(Ju, 2002; H.-R. Lee et al., 2009; Yoon, 2007).

이러한 연구들을 종합해 볼 때, 부모의 합리적인 양육행동 은 청소년의 학업지연행동에 직접적인 영향을 미치기도 하지 만, 청소년의 개인 내적변인인 자기 통제력을 변화시켜 학업 지연행동에 영향을 미칠 것으로 짐작해 볼 수 있다. 따라서 청 소년의 학업지연행동에 부모의 합리적 양육행동이 미치는 영 향을 더욱 잘 이해하기 위해서는 부모의 합리적 양육행동과 청소년의 학업지연행동 간의 관계를 매개하는 자기 통제력의 영향을 밝힘으로써 부모의 합리적 양육행동이 학업지연행동 의 변화를 초래하는 과정에 청소년의 자기 통제력의 증가와 같은 심리내적 변화가 수반되어 가능함을 제시해줄 필요가 있 다고 본다.

청소년의 자기 통제력은 욕구조절 및 과제완성과 같은 상 황에서 특히 요구되는 것이므로 모의 합리적 양육행동과 자기 통제력 간의 관계를 조절하는 변인으로써 내재적 동기를 들 수 있다.

Deci와 Ryan (2000) 은 자기결정성의 정도에 따라 동기의 유형을 무동기, 타율적 외재적 동기, 자율적 외재적 동기, 내재 적 동기라는 네 가지 유형으로 구분하였는데, 그 중에서 내재 적 동기는 최고의 자기결정성을 갖는 자율적 자기 결정적 행 동의 원형이다. 내재적 동기는 특별한 보상이 없더라도 자발 적으로 관심과 흥미를 가지고 학습하려고 하는 것으로 자기결 정적인 행동이며, 특정한 일이나 활동 자체에 대한 즐거움과 관심이라고 정의할 수 있다(K. Kim, 2016). 즉, 결과보다는 과 제수행 과정에 충실하며, 과제수행 과정에서 경험하는 즐거움 
을 보상으로 여긴다(Ryan \& Connell, 1989). 학업에 대한 행복 감, 즐거움, 생활만족도 등과 높은 관련이 있는 내재적 동기는 청소년의 자아존중감, 학업스트레스, 학업성취도 등에도 긍정 적인 영향을 주며 집중력에도 영향을 미치므로 대부분의 시간 을 공부를 하며 보내는 청소년에게 매우 중요한 요인 중 하나 라고 볼 수 있다(C. K. Kim \& Cho, 2014; H. Kim, 2012). 선행 연구에 따르면 자기결정성 이론에 따른 네 가지 동기의 유형 중, 내재적 동기군의 학생들이 학습동기가 가장 높은 것으로 나타났다(N.-H. Kim \& Lee, 2019). 이처럼 내재적 동기가 높 은 청소년은 보상이 없더라도 과제수행을 즐겁게 여기며 학업 장면에서도 스트레스를 덜 느끼고 학업적 성공을 이루기 쉬운 특성을 지니고 있으므로 모의 합리적 양육으로 인한 자기통제 력 발달이 촉진되기 쉬울 것이다. 즉 내재적 동기가 낮은 경우 보다 높은 청소년의 경우 어머니의 합리적인 양육행동으로 인 한 자기 통제력의 증가가 쉽게 이뤄지기 쉬움을 예측할 수 있 다. 따라서 청소년의 자기 통제력을 이해할 때 모의 양육행동 만이 아니라 내재적 동기를 함께 고려해 봄으로써 관계가 명 료화되리라 본다.

모의 양육행동은 모의 주관적인 판단보다는 자녀가 지각하 고 해석하는 방식에 따라 다르게 평가될 수 있기 때문에 본 연 구에서는 청소년이 지각한 모의 합리적 양육행동과 청소년의 학업지연행동 간의 관계에서 자기 통제력의 매개효과를 확인 하고, 그 과정에서 내재적 동기의 조절 역할을 확인하고자 매 개된 조절모형을 연구모형으로 설정하였다. 매개된 조절모형 이란 조절효과가 '왜' 어떻게 발생하는지 매개변수를 통해 밝 히고자 하는 것으로 독립변인, 조절변인, 상호작용변인이 종 속변인에 미치는 직접적 영향과, 이들 변인이 매개변인을 통 해 종속변인에 간접적으로 영향을 미치는 간접효과를 측정하 는 것이 목표가 된다. 즉, 모의 합리적 양육행동과 내재적 동기 가 상호작용하여 청소년의 자기 통제력에 영향을 미치고, 이 로 인한 조절효과가 자기 통제력을 매개로 하여 학업지연행동 에 영향을 미치는지를 본 모형을 통해 검증하고자 한다.

이를 통해 부모의 양육행동에 대한 코칭을 하며, 청소년의 내재된 동기를 높일 수 있는 방안을 강구하여 학업지연행동 예방에 도움이 되는 부모교육자료 및 효율적 방안을 제시하는 데 도움을 주고자 한다.

이상의 연구목적에 따른 연구문제와 연구모형은 Figure 1 과 같다.

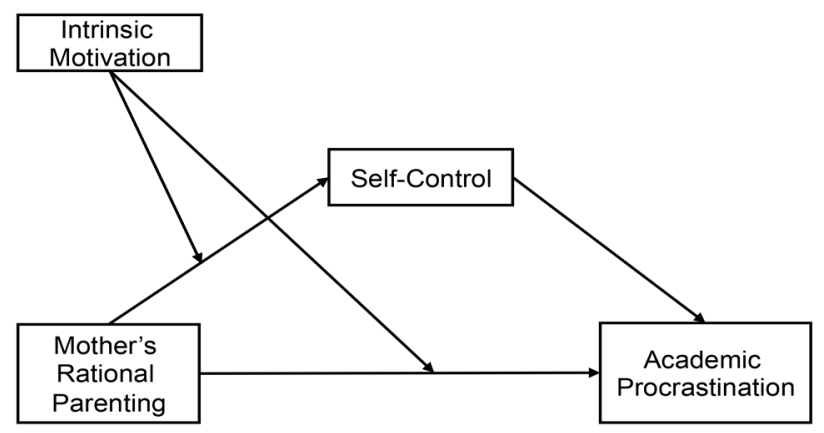

\section{연구문제 1}

내재적 동기가 모의 합리적 양육행동과 청소년의 학업지연 행동 사이에서 유의한 조절효과를 보이는가?

\section{연구문제 2}

자기 통제력이 모의 합리적 양육행동과 청소년의 학업지연 행동을 매개하는가?

\section{연구문제 3}

모의 합리적 양육행동, 자기통제력, 학업지연행동의 관계에서 내재적동기의 매개된 조절효과가 나타나는가?

\section{Methods}

\section{연구대상}

본 연구의 대상은 중학교 1,2학년 267명이다. 초등학교에서 중학교로 진학한 중학생은 대부분의 시간을 학교에서 보내 며, 방과 후에도 사교육을 받는 시간의 비중이 매우 높기 때문 에 학업지연행동이 일어날 수 있는 환경에 노출되어 있다. 연 구대상자의 인구학적 특성을 살펴본 결과 중학교 1학년 117 명(43.8\%), 중학교 2학년 150명(56.2\%)이었고, 남학생 139명 (52.1\%), 여학생 128 명(47.9\%)이었다.

\section{연구도구}

\section{학업지연행동}

학업지연행동을 측정하기 위해 Aitken (1982)의 지연행동척도 (aitken procrastination inventory)를 Ahn (2016)이 번안한 것을 사용하였다. 본 척도는 자기보고식으로, 총 15 문항으로 이루 어져있다. 각 문항은 전혀 그렇지 않다(1점)에서 매우 그렇다 
(5점)까지의 5점 Likert식 척도이다. 전체 15 문항 중 $2,4,6,11$, $12,14,15$ 번은 역 채점 문항으로, 점수는 15-75점 사이에 분포 된다. 점수가 높을수록 학업지연행동 수준이 높다는 것을 의 미한다. 문항의 예로는 "나는 마지막 순간까지 숙제 시작하기 를 미룬다.", "나는 종종 기한 내에 숙제를 끝마치지 못한다." 등이 있다. 본 연구에서 척도의 내적 합치도 Cronbach's $\alpha$ 값은 .76으로 나타났다.

\section{어머니의 양육행동}

어머니의 양육행동을 측정하기 위해 Oh와 Lee (1982)가 제작 한 부모양육행동 검사를 E. B. Ahn (2016)이 수정, 보완한 것을 사용하였다. 기존 척도는 두 가지 양육행동 각각 10 문항씩 총 20 문항으로 이루어져있으나 본 연구에서는 합리적 양육행동 10문항을 사용하였다. 5점 Likert식 척도로, 점수 범위는 10-50 점 사이이며 점수가 높을수록 자녀가 모의 양육행동을 합리적 인 양육행동이라고 지각함을 의미한다. 문항의 예로는 "공부 나 집안일을 돕는 것 등은 스스로 알아서 하도록 하신다.", "내 게 벌을 줄 때, 대게 그 이유를 설명해주신다." 등이 있다.

본 연구에서 척도의 내적 합치도 Cronbach's $\alpha$ 값은 .72로 나 타났다.

\section{자기통제력}

청소년의 자기 통제력을 측정하기 위해 Gottfresdon과 Hirschi (1990)의 자기통제력 척도와 H. S. Kim (1998)의 자기 통제평 정척도를 K. Y. Lee (2001)가 수정, 보완한 것을 사용하였다. 자 기보고식으로, 총 20문항이며 5점 Likert식 척도로 구성되어 있다. 점수 범위는 20-100점이며, 점수가 높을수록 자기 통제 력이 높은 것을 의미한다. 문항의 예로는 "나는 누가 지켜보지 않아도 규칙이나 지시를 잘 따른다.”, “나는 지루하고 재미없 는 일이라도 끝날 때 까지 그 일에 집중한다.” 등이 있다.

본 연구에서 척도의 내적 합치도 Cronbach's $\alpha$ 값은 .82로 나 타났다.

\section{내재적 동기}

Ryan과 Connell (1989)이 개발한 학업적 자기조절 질문지와 Hayamizu (1997)의 척도를 통합, 수정하여 한국의 일반적인 상황에 맞도록 수정된 $\operatorname{Kim}$ (2008)의 한국형 학업적 자기조 절 설문지(K-SRQ-A)를 사용하였다. 기존 척도는 통제적 동
기와 내재적 동기의 두 하위척도로 구성되어 있으나 본 연구 에서는 내재적 동기에 해당하는 12 문항만을 사용하였다. 5 점 Likert식 척도로 점수 범위는 12-60점이며 점수가 높을수록 내재적 동기가 높은 것을 의미한다. 문항의 예로는 "나는 공 부하면서 모르는 것들을 알아가기 위해 공부한다.”, “나는 지 식을 쌓아가는 것은 가치 있는 일이라고 믿기 때문에 공부한 다." 등이 있다.

본 연구에서 척도의 내적 합치도 Cronbach's $\alpha$ 값은 .93으로 나타났다.

\section{자료수집}

연구대상의 표집을 위해 부산광역시에 위치한 중학교 중 5개 학교를 임의 선정하여 학급단위로 표집 하였다. 본 연구자가 학교장의 동의를 얻어 직접 학급에 들어가 학생들에게 연구에 대해 설명하고 자료수집에 대한 동의를 구한 다음, 설문지 조 사를 실시하였다. 배부된 설문지 280 부 중 문항에 대한 응답 이 누락되었거나 불성실한 13 부를 제외한 267 부만을 최종 분 석 자료로 사용하였다.

\section{자료 분석}

수집된 자료는 SPSS 25 (IBM Co., Armonk, NY)와 Hayes (2013) 가 제안한 PROCESS macro의 model 8을 사용하여 분석하였 다. 먼저 SPSS 25 (IBM Co., Armonk, NY)를 사용하여 각 변인 들의 기술통계 및 상관분석을 실시하였다. 연구문제 1 번을 분 석하기 위해 다중회기 분석을 통한 모의 양육행동과 내재적 동기의 학업지연행동에 대한 상호작용 효과를 확인하고 유의 성을 검증하였다. 연구문제 2 번을 분석하기 위해 위계적 회귀 분석을 통한 모의 양육행동과 청소년의 학업지연행동 관계에 서 자기 통제력의 매개효과를 분석하였다. 끝으로 PROCESS macro의 model 8 을 사용하여 내재적 동기의 수준에 따라 모의 양육행동이 자기 통제력을 매개로 학업지연행동에 영향을 미 치는 매개된 조절효과를 확인하였다.

\section{Results}

\section{변인 간의 상관관계}

지각된 모의 합리적 양육행동, 학업지연행동, 자기통제력, 내 
Table 1

Correlations Among Mother's Parenting Behaviors, Academic Procrastination, Self-Control, Intrinsic Motivation

\begin{tabular}{|c|c|c|c|c|}
\hline & Rational parenting & $\begin{array}{c}\text { Academic } \\
\text { procrastination }\end{array}$ & Self-control & Intrinsic motivation \\
\hline Rational parenting & - & & & \\
\hline Self-control & $.38^{* *}$ & $-.58^{* *}$ & - & \\
\hline Intrinsic motivation & .17 & $-.38^{* *}$ & $.48^{* *}$ & - \\
\hline
\end{tabular}

Note. $N=267$.

${ }^{* *} p<.01$.

Table 2

Intrinsic Motivation as a Moderator of the Relationship Between Mother's Rational Parenting and Academic Procrastination

\begin{tabular}{|c|c|c|c|c|c|}
\hline \multicolumn{2}{|c|}{ Strp } & $\frac{\beta}{-.25}$ & $\frac{t}{-4.52^{* * *}}$ & $\begin{array}{l}R^{2} \\
.21\end{array}$ & $\frac{F}{34.60^{* * *}}$ \\
\hline & Intrinsic motivation (B) & -.35 & $-6.41^{* * *}$ & & \\
\hline \multirow{2}{*}{2} & Intrinsic motivation (B) & -.34 & $-6.07^{* * *}$ & & \\
\hline & $\mathrm{A} \times \mathrm{B}$ & -.10 & $-1.71^{* * *}$ & & \\
\hline
\end{tabular}

$\overline{* * *} p<.001$.

재적 동기간의 상관관계를 알아보기 위하여 Pearson의 상관계 수를 산출하였으며 그 결과는 Table 1 과 같이 나타났다.

Table 1 에 나타난 바와 같이, 모의 합리적 양육행동과 학업 지연행동 $(r=-.29, p<.01)$, 내재적 동기와 학업지연행동 $(r=$ $-.38, p<.01)$, 자기통제력과 학업지연행동 $(r=-.58, p<.01)$ 간 에 유의한 부적상관이 나타났다.

\section{모의 양육행동과 학업지연행동 간의 관계에 서 내재적 동기의 조절효과}

매개된 조절효과 분석을 위해서는 종속변인에 대한 독립변인 과 조절변인의 상호작용 효과가 우선 유의해야 하므로(Jeong $\& \mathrm{Seo}, 2016)$ 이에 대한 검증을 실시하고자 한다.

내재적 동기가 모의 양육행동과 학업지연행동 간에 조절효 과를 나타내는지 확인하기 위해 위계적 회귀분석을 실시하였 다. 분석에 앞서, 다중공선성 문제의 최소화를 위해 독립변수 와 조절변수의 평균중심화(mean centering)를 진행한 뒤 분석 에 사용하였다. 또한 잔차 간 자기상관 유무를 검토하기 위하 여 Durbin-Waston 계수의 값을 산출하였다. 계수의 값은 1.92 로 2에 근접하여 자기 상관은 없는 것으로 나타났다. 모의 양 육행동과 학업지연행동 간의 관계에서 내재적 동기의 중재효 과에 대한 결과는 Table 2와 같다.
모의 합리적 양육행동이 내재적 동기와 상호작용하여 청소 년의 학업지연행동에 미치는 영향력을 확인하기 위해 1 단계 에서는 모의 합리적 양육과 조절변인인 내재적 동기를 동시에 투입하고 2 단계에서는 모의 합리적 양육행동과 내재적 동기 의 상호작용 항을 투입한 결과 .01만큼의 $R^{2}$ 변화량을 가져왔 고, 이는 통계적으로 유의하였다 $(p<.001)$. 즉 모의 합리적 양 육행동이 학업지연행동에 미치는 영향은 내재적 동기의 수준 에 따라 달라진다고 볼 수 있다.

모의 합리적 양육행동과 내재적 동기의 상호작용 효과가 유의함에 따라 두 변인의 평균치를 기준으로 상-하 집단으로 구분하여 단순 기울기 분석을 실시하고 그 결과를 Figure 2에 제시하였다.

Figure 2에 의하면 내재적 동기가 낮을 경우보다 높을 경우 모의 합리적 양육의 증가에 따라 청소년의 학업지연행동이 낮 아지는 것으로 나타났다. 연속변수로 측정된 조절변수의 어 느 값에서 조절효과가 나타나는지 알아보기 위해 조절변인 수 준에 따른 회귀계수의 부트스트래핑 검증을 한 결과 Table 3과 같이 나타났다.

Table 3에서와 같이 내재적 동기가 낮은 경우 모의 합리적 양육행동이 1 만큼 높아질 때 학업지연행동은 .21 만큼 감소하 였고 $(B=-.21, p<0.5)$ 내재적 동기가 평균인 경우에는 모의 합리적 양육행동이 1 만큼 높아질 때 .32 만큼 감소하였다 $(B=$ 


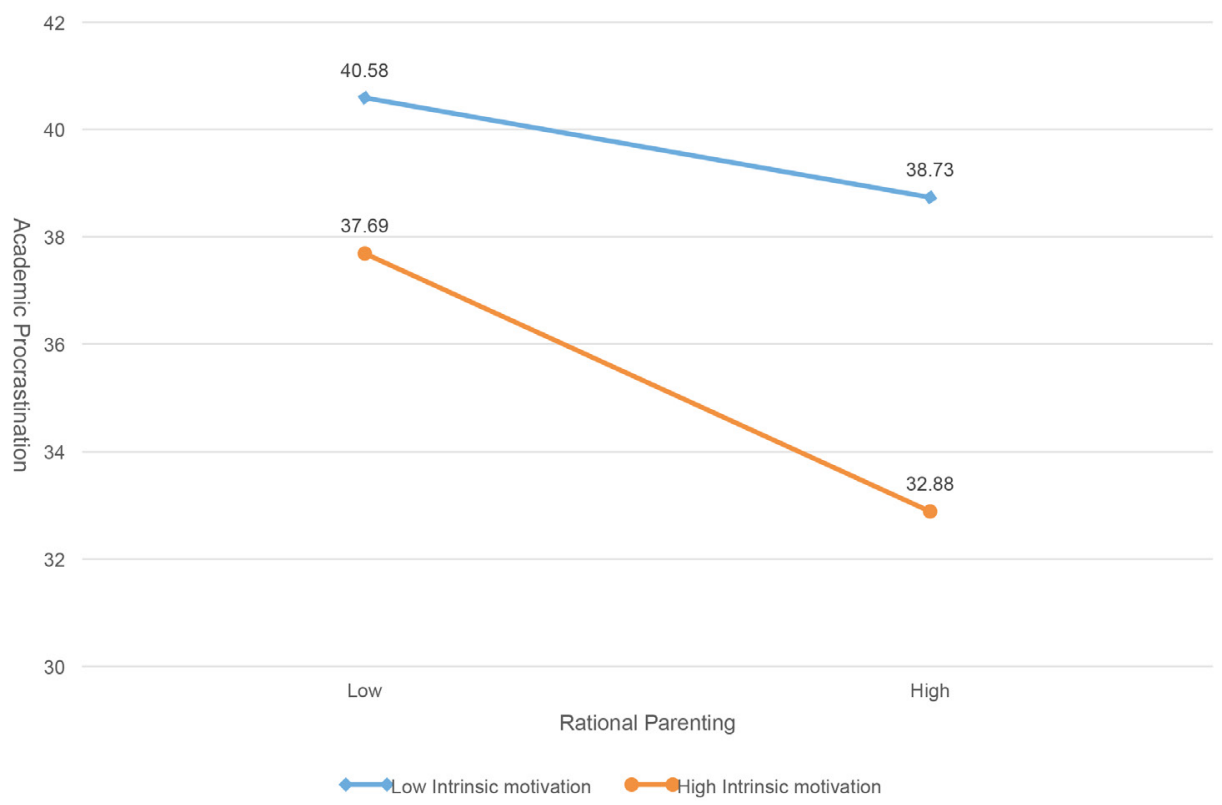

Figure 2. Intrinsic motivation as a moderator of the relationship between mother's rational parenting and academic procrastination.

Table 3

Significance of the Simple Slopes

\begin{tabular}{lccccc}
\hline & & & \multicolumn{2}{c}{$95 \%$ CI } \\
\hline Intrinsic motivation & $B$ & $S E$ & $t$ & LL & UL \\
\hline$-1 S D$ & -.21 & .09 & $-2.25^{*}$ & -.39 & -.03 \\
0 & -.32 & .07 & $-4.65^{* * *}$ & -.45 & -.18 \\
$+1 S D$ & -.45 & .11 & $-4.25^{* * *}$ & -.65 & -.24 \\
\hline
\end{tabular}

${ }^{*} p<.05 .{ }^{* * *} p<.001$.

$-.32, p<.01)$. 마지막으로 내재적 동기가 평균보다 높은 경우 모의 합리적 양육행동이 1 만큼 높아질 때 학업지연행동은 .45 만큼 감소하는 것으로 나타났으며, 이는 통계적으로 유의하였 다 $(B=-.45, p<.01)$. 조절효과에 대한 분석결과를 통해 내재 적 동기가 모의 합리적 양육행동이 청소년의 학업지연행동에 미치는 영향을 조절하고 있음을 확인할 수 있었다.

\section{모의 양육행동과 학업지연행동 간의 관계에서 자기 통제력의 매개효과}

모의 합리적 양육행동과 학업지연행동 간의 관계에 대한 자기 통제력의 매개효과를 검증하기에 다중회귀분석의 가정에 위 배되지 않았는지 확인하기 위해 변인들의 다중공선성 여부를 살펴본 결과, $\mathrm{VIF}(1.00 \sim 1.04)$ 가 10 이하, Tolerance (.96 1.00) 가 0.1 이상이므로 다중공선성은 존재하지 않는 것으로 나타 났다. 매개효과분석을 위해 Baron과 Kenny (1986)의 세 단계
접근 모델에 근거한 다중 회귀분석을 실시하였다. 이에 따르 면 매개효과를 입증하기 위해서는 독립변인, 매개변인, 종속 변인 간 유의한 상관관계가 있어야하고, 독립변인이 매개변인 에 유의한 영향을 미쳐야 하며, 종속변인에 독립변인과 매개 변인이 유의한 영향을 미쳐야 한다. 이 조건이 충족되었을 때 다음 회귀방정식을 통해 검증한다. 첫 번째로 매개변인에 대 한 독립변인의 영향력을 검증하고, 두 번째로 종속변인에 대 한 독립변인의 영향력을 검증한다. 마지막 세 번째로 종속변 인에 대한 독립변인과 매개변인의 영향력을 검증한다. 이 때 두 번째 회귀방정식에서 독립변인이 종속변인에 미치는 영향 력이 완전히 사라지면 완전매개 모형이 되고, 영향력은 유의 하지만 감소한다면 부분매개모형이 된다.

이에 따라 매개효과를 살펴본 결과는 Table 4와 같다.

Table 4 를 보면, 1 단계의 회귀모형에서 독립변인인 모의 합 리적 양육이 매개변인인 자기 통제력을 유의미하게 예측하고 있음을 확인할 수 있다 $(\beta=.39, p<.001)$. 그리고 2 단계의 회 
Table 4

Self-Control as a Mediator of the Relationship Between Mother's Rational Parenting and Academic Procrastination

\begin{tabular}{|c|c|c|c|c|c|}
\hline & Step & $\beta$ & $t$ & $R^{2}$ & $F$ \\
\hline 1 & Rational parenting $\rightarrow$ Self-control & .39 & $6.83^{* * *}$ & .15 & $46.60^{* * *}$ \\
\hline 2 & Rational parenting $\rightarrow$ Academic procrastination & -.29 & $-4.94^{* * *}$ & .08 & $24.40^{* * *}$ \\
\hline \multirow[t]{2}{*}{3} & Rational parenting $\rightarrow$ Academic procrastination & -.08 & -2.01 & .32 & $63.87^{* * *}$ \\
\hline & Self-control $\rightarrow$ Academic procrastination & -.54 & $-8.42^{* * *}$ & & \\
\hline
\end{tabular}

*** $p<.001$

Table 5

Bootstrapping Result for the Mediation Effect of Self-Control

\begin{tabular}{ccccc}
\hline & & \multicolumn{2}{c}{$95 \%$ CI } \\
\cline { 3 - 5 } & Effect & Boot SE & Boot LLCI & Boot ULCI \\
\hline Self-control & -.237 & .035 & -.299 & -.163 \\
\hline
\end{tabular}

Table 6

Direct, Indirect, and Total Effects, and Significant Validation of Indirect Effects

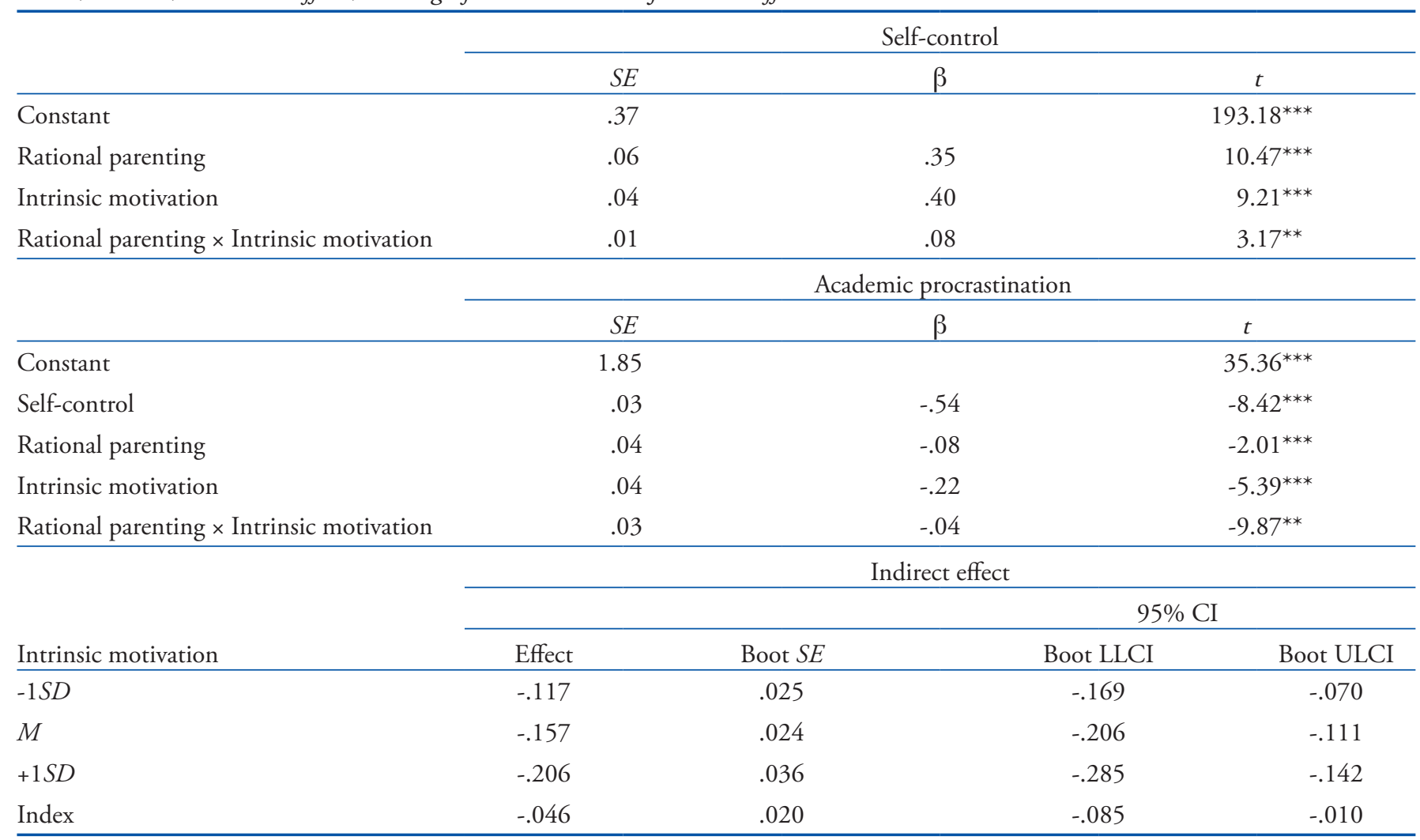

${ }^{* *} p<.01 .{ }^{* * *} p<.001$.

귀모형에서 모의 합리적 양육이 종속변인인 학업지연행동을 유의미하게 예측하고 있음을 알 수 있다 $(\beta=-.29, p<.001)$. 마 지막으로 3 간계 회귀모형에서 매개변인인 자기 통제력이 종 속변인인 학업지연행동을 유의미하게 예측하였고 $(\beta=-.54$, $p<.001)$, 매개변인인 자기 통제력을 통제한 후에 독립변인인 모의 합리적 양육행동이 종속변인인 학업지연행동에 미치는 유의한 영향이 완전히 사라졌다( $\beta=-.08$, n.s.). 그러므로 자기 통제력은 모의 합리적 양육과 학업지연행동 간의 관계에 대해 
완전 매개효과를 갖는다고 할 수 있다.

본 연구의 통계적 유의성을 검증하기 위해 Bootstrapping을 적용하여 확인하였다. Table 5 에서 Bootstrapping을 위해 재추 출한 표본 수는 1000 개였고, 이를 $95 \%$ 신뢰구간에서 구한 매 개효과 계수의 상한 값은 -.163, 하한 값은 -.299로 상한 값과 하한 값 사이에 0 을 포함하고 있지 않으므로 자기 통제력의 매 개효과가 통계적 무선오차에 의한 결과가 아님을 알 수 있다. 따라서 모의 합리적 양육행동이 자기 통제력을 매개로 하여 학업지연행동에 미치는 경로의 유의성이 확인되었다.

\section{매개된 조절효과}

다음으로 본 연구의 연구모형을 검증하기 위해 Preacher, Rucker 와 Hayes (2007)가 제시한 매개된 조절효과 분석방법에 따라 PROCESS macro의 model 8을 이용하여 연구모형을 분석하였다.

매개된 조절효과의 분석절차에 따라 연구문제 1 에서 조절 효과가 유의함을 분석하였다. 이에 대한 유의성이 밝혀졌으므 로 그 다음 분석으로 매개된 조절효과를 살펴보고자 한다.

매개된 조절 모형이란 조절효과가 매개변인을 경유하여 종 속변인에 미치는 효과를 보는 것으로 독립변인과 조절변인의 상호작용 항이 매개변인에 이르는 경로(직접효과)와 상호작 용 항이 매개변인을 거쳐 종속변인에 미치는 경로(간접효과) 가 유의함을 밝혀야 한다. 분석결과는 Table 6 과 같다.

Table 6에 의하면, 모의 합리적 양육행동과 내재적 동기의 상호작용변수는 자기 통제력을 유의하게 예측하였고 $(\beta=.08$, $p<.01)$, 자기 통제력은 학업지연행동에 유의미한 직접효과 를 보였다 $(\beta=-.54, p<.001)$. 다음으로 모의 합리적 양육과 내 재적 동기의 상호작용 변인이 자기 통제력을 매개로하여 학업 지연행동에 영향을 미치는 매개된 조절효과의 유의성을 검정 하기 위하여 부트스트랩 신뢰구간을 사용하여 조건부 간접효 과를 분석하였다. 분석결과, 모든 수준에서 $95 \%$ 신뢰구간에 0 을 포함하지 않으므로 조절변인의 모든 수준에서 매개된 조절 효과가 유의하였고 내재적 동기가 증가하면서 음의 간접효과 가 커짐을 알 수 있다. 간접효과 지수는 -.0464 (95\% CI [ -.0845 -.0102])이었다. 이러한 결과를 통해 모의 합리적 양육행동이 아동의 자기 통제력을 통해 학업지연행동에 미치는 간접 매개 효과가 아동의 내재적 동기에 의해 조절됨을 나타낸다. 즉 내 재적 동기가 높을수록 모의 합리적 양육이 아동의 자기 통제 력을 통해 학업지연행동에 영향을 미치는 매개효과가 크게 나 타나는 반면, 내재적 동기의 수준이 낮은 경우 이러한 매개효 과가 비교적 적게 나타남을 의미한다.

\section{Discussion}

본 연구의 목적은 중학생을 대상으로 모의 양육행동이 학업지 연행동에 미치는 영향에서 중학생의 내재적 동기에 의한 자기 통제력의 매개된 조절효과를 밝힘으로써, 청소년의 학업지연 행동 예방에 도움이 되는 부모교육자료 및 효율적 방안을 제 시하는데 도움을 주고자 한다.

연구문제에 따른 연구결과를 요약하고 논의하면 다음과 같다. 첫째, 모의 합리적 양육행동과 청소년의 학업지연행동은 내재적 동기에 의해 조절되는 것으로 나타났다. 모의 합리 적 양육행동과 학업지연행동의 관계에서 내재적 동기의 조 절효과는 내재적 동기가 높은 집단과 낮은 집단 모두에서 유 의한 것으로 나타났으나, 내재적 동기가 높은 집단일수록 학 업지연행동이 더욱 크게 감소하는 것을 확인할 수 있었다. 이 는 자녀의 학업지연행동 예방을 위한 모의 합리적 양육행동 의 효과는 자녀의 내재적 동기의 수준에 의해 결정되어짐을 제시해준다. 이는 모의 합리적 양육행동과 학업지연행동 간 의 관련성을 밝힌 연구결과(Yun \& Yeo, 2013)를 해석하는 과 정에서 모의 역할 중요성과 더불어 청소년의 내재적 동기를 함께 고려해야 함을 시사해준다. 따라서 청소년의 학업지연 행동 예방에 앞서 부모 및 교사는 결과보다 과제수행 과정에 충실하며 그 과정에서 오는 즐거움을 보상으로 느낄 수 있는 (Ryan \& Connell, 1989) 내재적 동기의 형성을 위한 개입에 관심을 둬야 할 것이다.

둘째, 모의 합리적 양육행동과 학업지연행동 간의 관계에 서 자기 통제력의 매개효과가 유의하게 나타났다. 즉, 청소년 의 학업지연행동에 모의 합리적인 양육행동이 직접적인 영향 을 주는 것이 아니라 어머니가 합리적으로 양육할 때 자녀의 자기 통제력이 높아지게 되고, 이로 인해 학업지연행동을 덜 하게 됨을 의미한다. 이러한 결과는 부모의 합리적인 양육행 동이 자기 통제력을 향상시키고 자기 통제력이 학업지연행동 을 감소시킨다는 선행연구와 맥을 같이 한다( Jin \& Lee, 2017; J. U. Kim \& Yang, 2013). 어머니가 지시에 대한 합리적인 이유 를 설명하고, 함께 의사결정을 함으로써 청소년들은 스스로 행동을 통제하고 조절할 수 있는 능력이 향상되며 이로 인해 정해진 시간 안에 과제를 완수하는 것이 가능하게 된다는 것 을 보여준다. 자기 통제력은 자기 주도적인 학습이 가능하게 하며, 학업 성취도를 올려준다는 선행연구( Jang \& Kim, 2011; T. G. Jeong, 2005)에 따라, 청소년의 학업지연행동을 예방하기 위해서는 합리적이고 자율적으로 양육하여 자녀의 자기 통제 력을 발달시키기 위해 노력해야 할 것임을 시사해 준다. 또한 
이는 청소년의 학업지연행동을 감소시키기 위한 모의 합리적 양육의 역할이해를 청소년의 자기 통제력과 관련시켜야 함을 제안해주므로 어머니 교육 자료로 활용될 수 있을 것이다.

마지막으로, 매개된 조절효과가 유의한 것으로 나타나 모 의 합리적인 양육행동과 청소년의 학업지연행동 간 관계에 대 한 자기 통제력의 매개효과가 내재적 동기에 따라 다르게 나 타남을 알 수 있다. 모가 합리적으로 양육할 때 청소년의 자기 통제력이 증가하고, 증가된 자기 통제력은 학업지연행동을 감 소시키는데 이러한 매개효과는 청소년의 내재적 동기가 커질 수록 더욱 크게 나타남을 알 수 있다. 이와 같은 결과는 내재 적 동기가 낮은 청소년보다 높은 청소년의 경우 어머니의 합 리적인 양육행동으로 인해 자기 통제력의 증가를 통해 학업 지연행동이 쉽게 감소됨을 의미한다. 이러한 결과는 청소년의 학업지연행동을 설명하기 위해 모의 합리적 양육행동(Zakeri, Esfahani, \& Razmjoee, 2013), 자기통제력( J. U. Kim \& Yang, 2013) 각각에 관심을 두고 이뤄진 연구들의 결과들을 통해 학 업지연행동을 이해하는데서 나타날 수 있는 한계점을 극복하 게 해주었다. 즉 학업지연행동 감소는 환경요인인 모의 합리 적 양육행동 그리고 청소년의 내재적 동기 및 자기 통제력과 같은 심리적 특성들의 어떠한 상호작용 및 과정을 통해서 가 능한지를 밝혀주었다. 본 연구결과는 학생들의 학업지연행동 이 어머니의 합리적 양육행동에 영향을 받지만 청소년의 개인 적 특성인 내재적 동기와 자기 통제력의 수준을 고려하지 않 고서 개입하는 것의 한계를 제안해주었다. 특히 학업지연행동 의 예방은 청소년 개인특성인 내재적 동기가 우선적으로 높아 야 함을 강조해주고 있다. 내재적 동기는 최고의 자기결정성 을 갖는 자율적 자기 결정행동의 원형으로 특별한 보상 없이 도 자발적으로 관심과 흥미를 가지고 학습하려고 하는 것이다 (Ryan \& Deci, 2000). 따라서 초등학교보다 학업에 대한 부담 이 증가하고(Anderman \& Midgley, 1997) 학교에서 보내는 시 간이 증가하는 중학생들이 자신의 진로를 위해 자발적 관심을 가질 수 있는 기회의 증대가 우선 제공되어야 할 것이다. 현재 시행되고 있는 자유학기제, 자유학년제의 효율적 운영과 청소 년 동기강화 프로그램의 적극 활용이 중요함을 알 수 있다.

이상의 논의를 종합해보면 모의 합리적 양육을 통해 청소 년의 자기통제력이 증가되고, 이를 통한 학업지연행동 감소를 위해서는 청소년을 대상으로 그들의 내재적 동기를 우선 강화 시켜야 한다는 것이다. 따라서 학업지연행동을 예방하기 위해 청소년의 내재적 동기를 강화할 수 있는 방안을 함께 모색하 면서 부모교육을 통해 실질적으로 청소년들에게 도움을 줄 수 있도록 노력해야 할 것이다.
본 연구의 의의는 학업에 많이 노출되어있는 청소년들이 학업지연행동을 감소시키기 위한 청소년 대상의 개입 안으로 우선 내재적 동기의 향상이 필요함을 밝힌 점과 학업지연행동 감소는 청소년의 내재적동기가 낮은 경우보다 높을 경우 가정 내 모의 합리적 양육이 청소년의 자기통제력 증가를 통해 쉽 게 이뤄질 수 있음을 제시한 점이다.

본 연구에서는 청소년의 학업지연행동에 영향을 미치는 환 경적 요인으로 부모 요인만을 선정하였다는 제한점이 있다. 청소년기에는 학교에서 보내는 시간이 늘어나고 부모 못지않 게 중요타인으로 또래와 교사 역할이 중요하므로 청소년의 학 업지연행동에 영향을 미칠 수 있는 학교 및 또래와 교사요인 의 영향을 탐색하는 것이 필요하다고 본다. 또한 성적, 가정환 경과 같이 학업지연행동에 영향을 미칠 수 있는 다양한 요인 들을 통제하지 않았다는 제한점이 있다. 성적을 비롯하여, 학 업지연행동에 영향을 줄 수 있는 다른 요인을 고려하여야 할 필요가 있을 것이다. 마지막으로, 본 연구의 목적이 기존의 연 구변인을 중심으로 매개된 조절효과를 밝히는 것이었으므로 기존에 사용한 측정도구를 그대로 사용하였다. 따라서 시의적 으로 적합한 문항이 반영되었는지에 대한 충분한 검토를 거치 지 못한 아쉬움이 있다. 추후 연구에서는 이를 감안하여 척도 문항에 대한 검토가 이루어졌으면 한다. 또한 초지식, 초연결 시대에 수동적으로 부여되는 학업을 수행하는 것도 중요하지 만 학교현장에서는 자기 주도적이고 창의적인 활동을 하는 것 역시 권장되고 있다. 따라서 추후 연구에서는 학업지연해동 특성 이외에 학업장면에서의 적응을 포괄적으로 이해한 연구 가 필요하다고 본다.

\section{Conflict of Interest}

No potential conflict of interest relevant to this article was reported.

\section{References}

\section{In English}

Aitken, N. D. (1982). College Stedent performance, satisfaction and retention: Specification and estimation of a structural model. The Journal of Higher Education. 53(1), 32-50. doi: 1 0.1080/00221546.1982.11780423 
Anderman, E. M., \& Midgley, C. (1997). Changes in achievement goal orientations, perceived academic competence, and grades across the transiton to middle-level schools. Contemporary Educational Psychology, 22, 269-298. doi:10.1006/ceps.1996. 0926

Baron, R. M., \& Kenny, D. A. (1986). The moderator-mediator variable distinction in social psychological research: Conceptual, strategic, and statistical considerations. Journal of Personality and Social Psychology, 51(6), 1173-1182.

Beswick, G., Rothblum, E. D., \& Mann, L. (1988). Psychological antecedents of student procrastination. Austrailian Psychologist, 23(2), 207-217. doi:10.1080/00050068808255605

Deci, E. L., \& Ryan, R. M. (2000). The "what" and "why" of goal pursuits: Human needs and the self-determination of behavior. Psychological Inquiry, 11(4), 227-268. doi:10. 1207/S15327965PLI1104_01

Ellis, A., \& Knaus, W. J. (1979). Overcoming procrastination: Or, how to think and act rationally in spite of life's inevitable hassles. New York: Signet.

Ferrari, J. R., \& Dianne, M. T. (2000). Procrastination as a selfhandicap for man and women: A task-avoidance strategy in a laboratory setting. Journal of Research in Personality, 34(1), 72-83. doi:10.1006/jrpe.1999.2261

Finkenauer, C., Engels, R. C. M. E., \& Baumeister, R. F. (2005). Parenting behavior and adolescent behavioral and emotional problems: The role of self-control. International Journal of Behavioral Development, 29(1), 58-69. doi:10. 1080/01650250444000333

Hayes, A. F. (2013). Introduction to mediation, moderation, and conditional process analysis: A regression based approach. New York: Guilford Press.

Lay, C. H. (1986). At last, my research article on procrastination. Journal of Research in Personality, 20(4), 474-495. doi:10. 1016/0092-6566(86)90127-3

Preacher, K. J., Rucker, D. D., \& Hayes, A. F. (2007). Addressing moderated mediation hypotheses: Theory, methods, and prescriptions. Multivariate Behavioral Research. 42(1), 185227. doi:10.1080/00273170701341316

Solomon, L. J., \& Rothblum, E. D. (1984). Academic procrastination: Frequency and cognitive behavioral correlates. Journal of Counseling Psychology, 31(4), 503-509. doi:10.1037/00220167.31.4.503

Tangney, J. P., Baumeister, R. F., \& Boone, A. L. (2004). High self-control predict good adjustment, less pathology, better grades, and interpersonal success. Journal of Personality, 72(2), 271-324.

Ryan, R. M., \& Connell, J. P. (1989). Perceived locus of causality and internalization: Examining reasons for acting in two domains. Journal of Personality and Social Psychology, 57(5), 749-761. doi:10.1037/0022-3514.57.5.749
Zakeri, H., Esfahani, B. N., \& Razmjoee, M. (2013). Parenting styles and academic procrastination. Social and Behavioral Sciences, 84, 57-60. doi:10.1016/j.sbspro.2013.06.509

\section{In Korean}

Ahn, E. B., \& Kim, H. W. (2016). The effect of parenting behavior on academic procrastination of early adolescence: Mediation effect of self-control and time management capabilities. Youth Facilities and Environment, 14(1), 5-14.

Choo, S.-Y., \& Lim, S.-M. (2008). The relationship between fear of failure and academic procrastination: The mediating effects of avoidance goals and cognitive volition control, and the moderating effects of parental achievement pressure and parental psychological control. Korea Journal of Youth Studies, 19(4), 169-198.

Hwang, I.-S. (2008). The relationship between perceived parenting styles and academic procrastination mediated by self-efficacy and perfectionism (Master's thesis). Retrieved from http:// www.riss.kr/link?id=T11431414

Hwang, I.-S., \& Jang, S.-S. (2010). The relationship between perceived parenting styles and academic procrastination mediated by self-efficacy and perfectionism. Journal of Student Guidance and Counseling, 28, 25-43.

Jang, S. H., \& Kim. O. J. (2011). The effects of school adjustment and self-control on self-directed learning ability of adolescents. The Journal of Learner-Centered Curriculum and Instruction, 11(3), 159-179.

Jeong, T. G. (2005). The effects of internet addiction and self control on achievement of elementary school children. The Journal of Yeolin Education, 13(1), 143-163.

Jin, E., \& Lee, K. (2017). The mediating effects of self-control in the relationship between perceived parenting attitude and adolescents' smartphone addiction. The Journal of Educational Infromation and Media, 23(4), 683-708. doi:10.15833/KAFEIAM.23.4.683

Ju, D.-B. (2002). The impacts of maternal employment and perceived parenting style on the early adolescent's selfcontrol and self-concept. Korean Journal of Youth Studies, 9(2), 23-43.

Kim, A. Y. (2008). The development of academic motivation among korean adolescents. Korean Journal of Psychological and Social Issues, 14(1), 111-134.

Kim, C. K., \& Cho, M. K. (2014). A structural analysis of parental attachment, self-determination, academic stress and self-efficacy by child. Journal of Emotional \& Behavioral Disorders, 30(2), 337-359.

Kim, H. (2012). The effect of girl's highschool students' intrinsic motivation and parental learning involvement on academic achievement: Focused on the mediating effect of self-regulated 
learning ability (Master's thesis). Retrieved from http:// www.riss.kr/link?id=T12948535

Kim, J. U., \& Yang, M. J. (2013). The influence of self-control, self-efficacy, and depression on procrastination of college students. The Korea Journal of Youth Counseling, 21(2), 247265.

Kim, K. (2016). Analysis of structural relations between elementary gifted child's creative disposition and parent-child relationship, parent's involvement in child's learning, and intrinsic motivation (Doctoral thesis). Retrieved from http://www. riss.kr/link?id=T14196179

Kim, N.-H., \& Lee, T.-H. (2019). Effect of a specialization program based on self-determination theory on learning motivation and self-efficacy in a specialized vocational high school: With priority given to experiential learning at a hotel. International Journal of Tourism and Hospitality Research, 33(3), 85-97. doi:10.21298/IJTHR.2019.3.33.3.85

Lee, H.-R., Doh, H.-S., Kim, M-J., \& Park, D.-K. (2009). Pathways from maternal parenting behavior to adolescents' internet addiction mediating effects of adolescents' selfcontrol and depression/anxiety. Korean Journal of Child Studies, 30(2), 97-112.

Lee, K.-N. (2000). Study for the development of child self-control rating scale. The Korean Journal of the Human Development, 7(1), 99-120.

Lee, K. W. (2001). Study on internet addiction of adolescent (Doctoral thesis). Retrieved from http://www.riss.kr/link?id $=\mathrm{T} 8156536$

Myung, H. W., Lee, S. M., Yang, N. Y., \& Lee, J. H. (2016). The moderation effect of help-seeking on the relationship between maladaptive perfectionism and academic procrastination behavior of middle school students. The Korea Journal of Youth Counseling, 24(2), 201-219.

Oh, S. S., \& Lee, J. S. (1982). The relationships between children's perception of parental discipline and affective characteristics of the cildren. Korea Insitute for Research in the Behavioral Sciences, 11(1), 1-15.

Roh, Y.-S. (2011). The effect of high school students' achievement goal orientation on academic stress: Focusing on the mediation effect of academic procrastination. (Master's thesis). Retrieved from http://www.riss.kr/link?id=T12516949

Park, H., \& Ahn, D. (2019). The mediating effect of volitional control and academic self-efficacy on the relationships between perceived mother's parenting style and high school students' academic procrastination. The Korea Educational Review, 25(2), 92-116.

Park, S. H., Ham, J. M., \& Son, W. S. (2016). Relationships of achievement goal orientation with academic procrastination: A person-centered approach. Asian Journal of Education, $17(2), 127-149$.

Seo, J. E. (2012). The relationship between parenting styles and children's procrastination: The mediating effects of anger suppression and depression (Master's thesis). Retrieved from http://www.riss.kr/link?id=T12708475

Synn, M.-H., Park, S.-H., \& Seo, E.-H. (2005). The relation between self-regulated learning and procrastination. Korean Journal of Educational Research, 43(4), 227-292.

Wu, C., \& Ahn, D. (2017). The relationship between helicopter parenting, self-regulated learning, autonomy and academic procrastination of high school student in Korea and China. Journal of Education \& Culture, 23(6), 317-340. doi:10.24159/joec.2017.23.6.317

Yang, M. J. (2017). The effects of evaluative concerns perfectionism and goal orientation on college students academic procrastination. Korean Association For Learner-Centered Curriculum And Instruction, 17(2), 393-407. doi:10.22251/ jlcci.2017.17.2.393

Yoon, Y. S. (2007). A study on self-regulatory ability of adolescents and its relationship with personality, parenting, behavior problems, and life stress (Doctoral thesis). Retrieved from http://www.riss.kr/link?id=T10989802

Yun, K., \& Yeo, T. (2013). The mediation effects of multidimensional perfectionism on the relationship between mother's parenting style and academic procrastination among the upper graders in elementary school. The Korean Journal of Elementary Counseling, 12(1), 87-107.

\section{ORCID}

Eun Byeol Ahdn https://orcid.org/0000-0002-7327-6214

Hee Hwa Kim https://orcid.org/0000-0003-0829-3226

Received December 31, 2019

Revision received March 4, 2020

Accepted March 23, 2020 